\title{
Serum neuron-specific enolase and SIO0 calcium binding protein B biomarker levels do not improve diagnosis of acute stroke
}

\author{
${ }^{1} \mathrm{~S}$ González-García, ${ }^{2} \mathrm{~A}$ González-Quevedo, ${ }^{1} \mathrm{M}$ Peña-Sánchez, ${ }^{1} \mathrm{C}$ Menéndez-Saínz, \\ ${ }^{1} \mathrm{R}$ Fernández-Carriera, ${ }^{3} \mathrm{M}$ Arteche-Prior, ${ }^{3} \mathrm{~A}$ Pando-Cabrera, ${ }^{3} \mathrm{O}$ Fernández-Concepción \\ ${ }^{1}$ Researcher; ${ }^{2}$ Professor; ${ }^{3}$ Neurologist, Instituto de Neurología y Neurocirugía Habana, Cuba
}

\section{ABSTRACT}

Background: The high sensitivities and specificities reported for blood biomarkers as a supportive test in the diagnosis of acute stroke do not correspond with their performance for decision-making in emergency situations.

Methods: Seventy-two patients with suspected stroke were recruited: 44 with ischaemic stroke, 17 with haemorrhagic stroke and II stroke mimics, as well as a high-risk control group of 79 individuals. Serum neuron-specific enolase (NSE) and SIO0 calcium binding protein B (SIOOB) biomarker levels were determined on admission, using immunoassay kits. The sensitivities and specificities of NSE and SIOOB for distinguishing acute stroke from stroke mimics and high-risk controls were calculated.

Results: For cut-off values (NSE $\leq 14$ micrograms per litre and SIO0B $\leq 130$ nanograms per litre) the sensitivity was $53 \%$ and $55 \%$ respectively. Specificity was 64 for both versus the stroke mimic group. Specificity was higher $(79 \%$ and $86 \%$ respectively) when calculated on the basis of the control group.

Conclusions: This study supports the evidence indicating that serum levels of NSE and SIOOB do not improve the diagnosis of acute stroke.

KEYWORDS Neuron-specific enolase, SI00 calcium binding protein B, stroke, specificity, sensitivity, biomarker

DECLARATION OF INTERESTS No conflicts of interest declared.
Correspondence to $S$ González-García

Departamento de Neurobiología Instituto de Neurología y Neurocirugía,

Calle 29 esquina D. Vedado,

Habana CP 10400, Cuba

tel. (537) 8345517

e-mail sergiogg@infomed.sld.cu

\section{INTRODUCTION}

The assessment of stroke in emergency settings has typically been done by clinicians in combination with neuroimaging. However an expert clinician is not always available and while computed tomography (CT) scans accurately distinguish brain ischaemia and haemorrhage, they may take some time to perform and the results are frequently normal even in cases of confirmed ischaemic stroke. ${ }^{1,2}$ The availability of a blood biomarker to support a clinical diagnosis of stroke would be valuable, especially in specific situations where imaging resources are limited, such as in pre-hospital facilities where the physician has to rapidly identify ischaemic stroke in order to accelerate access to treatment.

In Cuba, a network of 22 stroke units treat many patients with acute stroke. They are located in secondary or tertiary hospitals and have trained staff and basic equipment for the diagnosis and management of stroke patients. However, these patients are also treated by emergency services, in the ambulance and in primary care centres by general practitioners.

The diagnosis of stroke can be challenging because of the variety of aetiological processes involved in stroke pathophysiology, the numerous symptoms that can be displayed and the variety of stroke mimics such as brain tumours, seizures, hemiplegic migraine or hypoglycaemia which often appear in an emergency department. The levels of several biomarkers in the blood following brain injury have been evaluated for use in distinguishing acute stroke from stroke mimics, but the successful translation to a biomarker useful in clinical practice has proven difficult, as they are not specific and many disease processes can damage brain tissue. The two molecules which have been most extensively assessed for the diagnosis and prognosis of stroke are SIO0 calcium binding protein $\mathrm{B}(\mathrm{S} / 00 \mathrm{~B})$ and neuron-specific enolase (NSE) but the high sensitivities and specificities reported in the scientific literature often do not correspond with the practical performance of these and other blood markers. $^{3}$ Many studies have concentrated on distinguishing a stroke patient from a healthy control subject when evaluating blood markers of brain injury. Perhaps a more relevant issue is whether stroke can be distinguished from stroke mimics. ${ }^{3,4}$

Another difficulty in the use of these biomarkers for the diagnosis of acute ischaemic stroke is the reported elevation of SIOOB and NSE levels in the blood of hypertensive patients when compared to healthy controls. ${ }^{5}$ Since hypertension is the most frequent risk factor for stroke, this issue should be considered and could provide additional diagnostic validation. 
S González-García, A González-Quevedo, M Peña-Sánchez, C Menéndez-Saínz, R Fernández-Carriera, M Arteche-Prior, A Pando-Cabrera, O Fernández-Concepción

The object of our study was to evaluate the specificity and sensitivity of serum SIOOB and NSE for distinguishing stroke patients from: I) patients with suspected stroke on arrival to the emergency room but a final diagnosis of transient ischaemic attack (TIA) or stroke mimics, and 2) a control group with a similar percentage of hypertensive individuals as the stroke group, but without a history of neurological disease.

\section{PATIENTS AND METHODS}

\section{Patients}

Seventy-two patients with suspected stroke (from 8-48 hours of symptom onset) were consecutively recruited in the stroke unit. 'Suspected stroke' was defined by the medical practitioner on duty in the emergency room based on the sudden appearance of a focal neurological deficit. The patient was then sent to the stroke unit where a trained neurologist determined admission based on clinical examination and a computed tomography (CT) scan of the brain. The diagnosis was later confirmed with the subsequent identification of a lesion consistent with the symptoms. All the patients were treated according to the Cuban Guidelines for Cerebrovascular Diseases. ${ }^{6}$

A total of 44 patients were confirmed as having an ischaemic stroke, 17 with a haemorrhagic stroke and II patients were diagnosed as having a TIA or as stroke mimics. The patients presenting as stroke mimics had one of two diagnoses: brain metastasis or hypertensive emergency. Ischaemic and haemorrhagic stroke patients were combined as a stroke group to evaluate the effectiveness of NSE and SIOOB levels in differentiating stroke from stroke mimics and TIA.

Hypertension is the main risk factor for all types of stroke so we established a control group ('high-risk') with similar age and co-morbidities as the stroke patients (hypertension and/or diabetes mellitus). This high-risk control group consisted of 79 individuals who were referred by their general practitioner mainly because of headache, suspected epilepsy, lumbosacral pain and dizziness. Fifty-four patients with essential hypertension and 25 normotensive patients were included in this group in order to obtain a prevalence of approximately $70 \%$ with hypertension (as occurs in stroke). No neurological disease was confirmed and there was no history of previous neurological disorders.

Although the levels of SIOOB and NSE biomarkers are highly specific for brain tissue, they are also expressed in other cell types under certain physiological and pathological conditions. For this reason, patients and members of the control group with clinical evidence of other neurological diseases, known malignancies, chronic inflammatory diseases, recent infection or trauma were not included.
We interviewed all patients and members of the control group in order to establish their personal pathological history and medication used. The patients or their relatives and the control subjects gave signed informed consent prior to entering the study. It was conducted according to the revised Declaration of Helsinki (1998) and approved by the Ethics Committee of the Institute of Neurology and Neurosurgery in the Cuban Ministry of Public Health in Havana.

\section{Data collection}

Computed tomography scans were performed on admission and within 48-72 hours after the onset of symptoms in order to define the size and location of the ischaemic or haemorrhagic lesion.

Patient co-morbidities were collected from clinical records using the following criteria: hypertension $(>140$ milimetres of mercury [mmHg] systolic, $>90 \mathrm{mmHg}$ diastolic or currently prescribed anti-hypertensive medication); diabetes mellitus (spontaneous blood sugar level $>\mathbf{2 0 0}$ miligrams per deciliter $[\mathrm{mg} / \mathrm{dL}$ ] or currently prescribed diet or anti-diabetic medication); hyperlipidaemia $(>220 \mathrm{mg} / \mathrm{dL}$ total cholesterol or $>150$ $\mathrm{mg} / \mathrm{dL}$ triglyceride).

\section{Blood sampling and analytical procedures}

Blood was drawn from patients (12-48 hours after symptom onset) and from control subjects and was collected in ethylenediaminetetraacetic acid and dry tubes. Each participant received a consecutive number which was assigned to the blood samples. This blood was tested for general haematological results and an erythrocyte sedimentation rate. Serum was obtained by centrifugation and stored at $-20^{\circ} \mathrm{C}$ until analysis was done. Routine haematological and hemochemical analyses were performed (haemoglobin, haematocrit, leukocyte count, glucose, creatinine, urates, lipid profile, total proteins, aspartate aminotransferase, alanine aminotransferase and $\gamma$-glutamyltransferase). The results of the blood workup in control subjects and stroke patients did not reveal other possible associated pathologies. Serum SIOOB and NSE levels were determined using immunoassay kits $\mathrm{CanAg}$ SIO0 EIA (708-10) and CanAg NSE ElA (420-10) from CanAg Diagnostics AB (Sweden) as described elsewhere. ${ }^{5}$

\section{Statistical analysis}

Demographic, clinical and laboratory frequency variables were calculated. Continuous variables were tested for normal distribution using the Kolmogorov-Smirnov test. Medians and interquartile ranges were calculated for biomarker concentrations and differences between groups were assayed using the Mann-Whitney $U$, Wilcoxon matched pair or Kruskal-Wallis tests. The 
relationship between sensitivity and specificity for stroke versus TIA+mimics and vs controls was calculated by receiver-operating characteristics (ROC) analysis. The 'optimum' cut-off values from the ROC curve (considered as the point at which the sum of sensitivity and specificity is maximal) were calculated for each protein. These values were also used to distinguish stroke from highrisk control subjects. Statistical calculations were performed with Statistica 6.0 for Windows. Significance was considered in all instances when $\mathrm{p}<0.05$.

TABLE I Clinical and demographic characteristics of the study groups

\begin{tabular}{|l|c|c|c|}
\hline Variable & $\begin{array}{l}\text { Stroke } \\
(\mathbf{I S + H S )} \\
(\mathbf{n = 6})\end{array}$ & $\begin{array}{l}\text { High-risk } \\
\text { control } \\
(\mathbf{n = 7 9 )}\end{array}$ & $\begin{array}{l}\text { TIA+ } \\
\text { mimics } \\
(\mathbf{n = 1} \text { I) }\end{array}$ \\
\hline Age (years) & $\begin{array}{c}68.0 \\
(32-88)\end{array}$ & $\begin{array}{c}61.3 \\
(30-98)\end{array}$ & $\begin{array}{c}65.7 \\
(42-83)\end{array}$ \\
\hline $\begin{array}{l}\text { Female gender } \\
\mathrm{n}(\%)^{*}\end{array}$ & $\begin{array}{c}23 \\
(38.3 \%)\end{array}$ & $\begin{array}{c}46 \\
(58.2 \%)\end{array}$ & $\begin{array}{c}4 \\
(44.4 \%)\end{array}$ \\
\hline $\begin{array}{l}\text { Hypertension } \\
\mathrm{n}(\%)\end{array}$ & $\begin{array}{c}46 \\
(75.4 \%)\end{array}$ & $\begin{array}{c}54 \\
(68.5 \%)\end{array}$ & $\begin{array}{c}9 \\
(81.8 \%)\end{array}$ \\
\hline $\begin{array}{l}\text { Diabetes mellitus } \\
\mathrm{n}(\%)\end{array}$ & $\begin{array}{c}14 \\
(27.5 \%)\end{array}$ & $\begin{array}{c}22 \\
(35.5 \%)\end{array}$ & $\begin{array}{c}\mathrm{I} \\
(11.1 \%)\end{array}$ \\
\hline $\begin{array}{l}\text { Obesity } \\
\mathrm{n}(\%)\end{array}$ & $\begin{array}{c}17 \\
(34.0 \%)\end{array}$ & $\begin{array}{c}31 \\
(49.2 \%)\end{array}$ & $\begin{array}{c}3 \\
(37.5 \%)\end{array}$ \\
\hline $\begin{array}{l}\text { Previous cardiac } \\
\text { disease }{ }^{\ddagger} \mathrm{n}(\%)\end{array}$ & $\begin{array}{c}31 \\
(56.4 \%)\end{array}$ & $\begin{array}{c}10 \\
(13.8 \%)\end{array}$ & $\begin{array}{c}3 \\
(37.5 \%)\end{array}$ \\
\hline
\end{tabular}

IS= Ischaemic stroke; HS= Haemorrhagic stroke;

$\mathbf{T I A}=$ Transient ischaemic attacks

Age $=$ mean (range)

"Analysis of variance between groups (ANOVA) (Age):

$F=5.04 ; p=0.0076$. Post hoc (Tukey): Stroke versus control

$\mathrm{p}=0.0045$ (different letters denote significant difference)

"Pearson $\chi^{2}$ test (female gender) $\chi^{2}=7.09 ; \mathrm{p}=0.03$

*Pearson $\chi^{2}$ test (previous cardiac disease) $\chi^{2}=26.40$; $\mathrm{P}=0.0000$

"Percentages were calculated in the cases where comorbidity information was available.

\section{RESULTS}

The clinical and demographic characteristics of the patients with confirmed stroke, high-risk controls and TIA+mimics are presented in Table I.

Although differences were observed with respect to age and gender between the study groups, no differences in serum NSE and SIOOB levels were previously reported for these characteristics. ${ }^{5}$ The higher percentage of previous cardiac disease in the stroke patients was an expected finding.

The median and interquartile range of serum NSE and SIOOB levels in the three study groups are presented in Table 2.When analysed independently (four study groups), the Kruskal-Wallis (post hoc) test only revealed a significant difference between stroke and control groups,
TABLE 2 Serum NSE and SIO0B concentrations in the study groups

\begin{tabular}{|l|l|l|l|}
\hline $\begin{array}{l}\text { Marker } \\
\text { levels }\end{array}$ & $\begin{array}{l}\text { Stroke } \\
(\text { IS+HS }) \\
(\mathbf{n}=6 \mathrm{I})\end{array}$ & $\begin{array}{l}\text { High-risk } \\
\text { control } \\
(\mathbf{n = 7 9 )}\end{array}$ & $\begin{array}{l}\text { TIA+ } \\
\text { mimics } \\
(\mathbf{n}=\mathrm{II})\end{array}$ \\
\hline $\begin{array}{l}\mathrm{NSE}^{* *} \\
(\mu \mathrm{g} / \mathrm{L})\end{array}$ & $\begin{array}{c}15.0 \\
(9.7-22.4)\end{array}$ & $\begin{array}{c}9.5 \\
(5.8-13.0)\end{array}$ & $\begin{array}{c}6.0 \\
(5.4-21.5)\end{array}$ \\
\hline $\begin{array}{l}\mathrm{SIOOB} \\
(\mathrm{ng} / \mathrm{L})\end{array}$ & $\begin{array}{c}\mid 42.5 \\
(I 03.0-214.3)\end{array}$ & $\begin{array}{c}76.0 \\
(53.6-106.6)\end{array}$ & $\begin{array}{c}\mid 17.0 \\
(97.0-153.0)\end{array}$ \\
\hline
\end{tabular}

IS= Ischaemic stroke; HS= Haemorrhagic stroke;

TIA $=$ Transient ischaemic attacks

NSE and SI OOB= median (interquartile range)

$\boldsymbol{\mu g} / \mathbf{L}=$ micrograms per litre

ng/L= nanograms per litre

NSE= Kruskal-Wallis: $\mathrm{H}(2, n=152)=22.09 ; p=0.0000$

Post hoc: stroke vs control: $p=0.0000$

* S I 00B = Kruskal-Wallis: H (2, $n=150)=40.21 ; p=0.0000$

Post hoc $=$ Stroke vs control: $\mathrm{p}=0.0000$;

TIA+mimics vs control: $p=0.0265$

but not with TIA and mimics. Thus, due to the small sample size TIA and mimics were combined into one group.

Concentrations of NSE were significantly higher in patients with stroke (IS+HS) than in control subjects, while there were no differences in TIA+mimics. Concentrations of SIOOB in serum were significantly higher in patients with stroke than in controls, and also in TIA+mimics with respect to controls (Table 2). No difference between stroke and TIA+mimics was found. Levels of NSE and SIOOB were significantly correlated in stroke patients (Figure I), but not in controls $(p=0.235)$, nor in stroke mimics $(p=0.715)$.

For confirmed stroke vs high-risk control subjects, the optimum cut-offs for the two analytes as obtained by ROC curve analysis were $14 \mu \mathrm{g} / \mathrm{L}$ for NSE and $130 \mathrm{ng} / \mathrm{L}$ for SI00B. Patients in the three study groups were classified as having a positive or negative result with respect to these cut-off values (Table 3 ).

TABLE 3 Number of patients with positive or negative results according to NSE and SIOOB cut-off values in the study groups

\begin{tabular}{|c|c|c|c|c|}
\hline \multirow{2}{*}{$\begin{array}{l}\text { Study } \\
\text { groups }\end{array}$} & \multicolumn{2}{|c|}{ NSE ( $\mu \mathrm{g} / \mathrm{ml})$} & \multicolumn{2}{|c|}{ SIOOB (ng/ml) } \\
\hline & $+(>14)$ & $-(\leq 14)$ & $+(>130)$ & $-(\leq 130)$ \\
\hline $\begin{array}{l}\text { Stroke } \\
(6 I)\end{array}$ & 35 & 26 & 34 & 27 \\
\hline $\begin{array}{l}\text { TIA+mimics } \\
\text { (II) }\end{array}$ & 4 & 7 & 5 & 6 \\
\hline $\begin{array}{l}\text { Control } \\
\text { (79) }\end{array}$ & 19 & 60 & 16 & 63 \\
\hline \multicolumn{5}{|c|}{$\begin{array}{l}\text { TIA = Transient ischaemic attacks } \\
\boldsymbol{\mu g} / \mathbf{L}=\text { micrograms per litre } \\
\mathbf{n g} / \mathbf{L}=\text { nanograms per litre }\end{array}$} \\
\hline
\end{tabular}


S González-García, A González-Quevedo, M Peña-Sánchez, C Menéndez-Saínz, R Fernández-Carriera, M Arteche-Prior, A Pando-Cabrera, O Fernández-Concepción

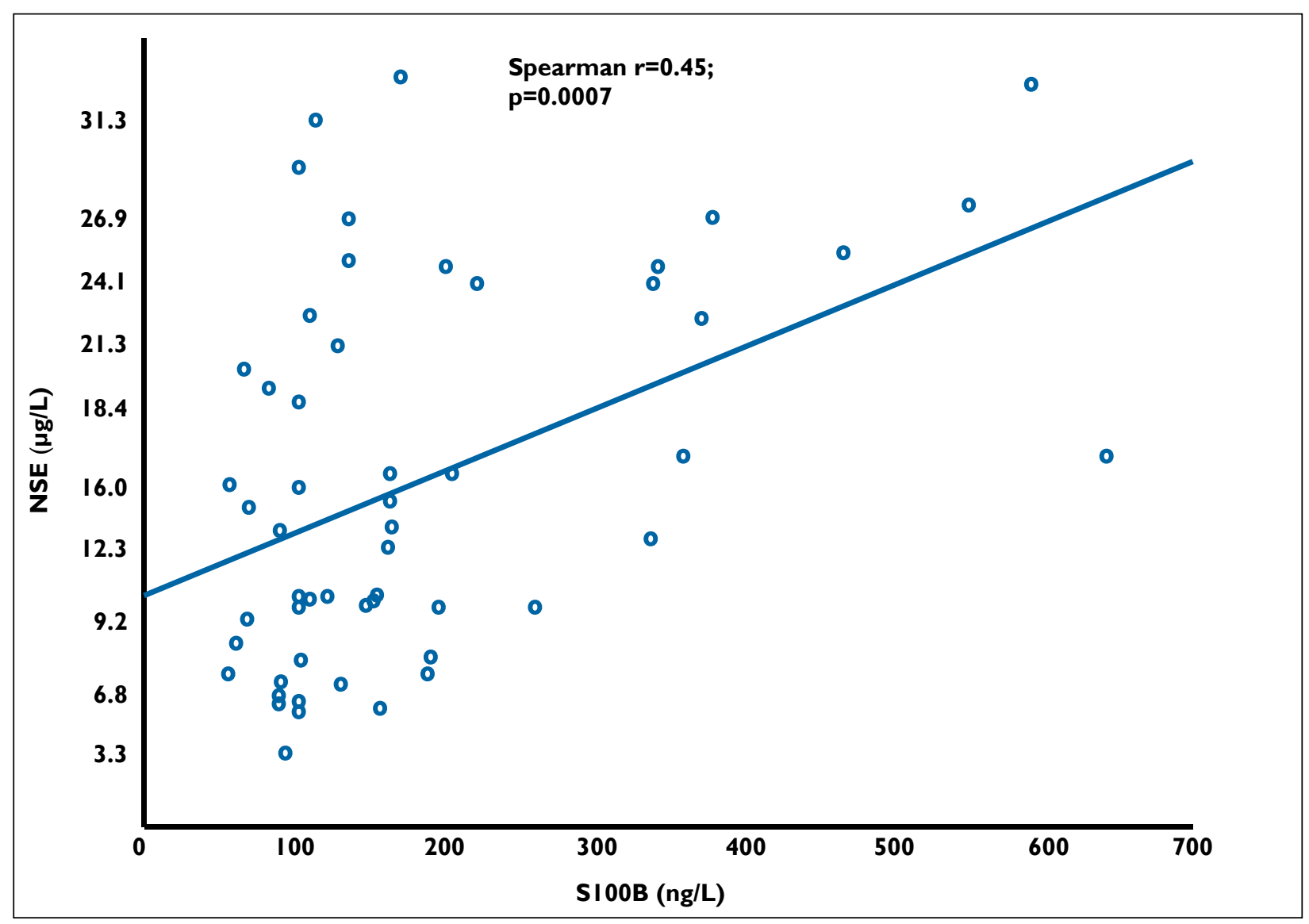

FIGURE I Correlation between neuron-specific enolase and SI00 calcium binding protein B levels in stroke patients.

The sensitivity and specificity for NSE and SIOOB for distinguishing stroke from TIA+mimics and stroke from high-risk control subjects were determined by ROC curve analysis. The area under the ROC curves showed that NSE and SIOOB differentiated confirmed stroke patients from high-risk controls with a sensitivity of $53 \%$ and $55 \%$ and a specificity of $79 \%$ and $86 \%$ respectively, but did not differentiate them from TIA+mimics (Table 4).

As expected, specificity was higher for NSE and SIOOB when comparison was versus the control group than versus the TIA+mimics group (64\% for both proteins).

\section{DISCUSSION}

Though many proteins are associated with stroke, successful translation into a biomarker useful in clinical practice for differential diagnosis has proven difficult. ${ }^{7}$ Some of the challenges for the diagnosis of stroke are the heterogeneity of stroke itself and the number and variety of stroke mimics. ${ }^{8}$ Raised levels of NSE and SIOOB were found in this study when compared to highrisk control subjects (with a prevalence of arterial hypertension and diabetes mellitus), where an elevation of these proteins had been previously reported. ${ }^{5}$ Nevertheless, serum NSE and SIOOB in cases of

TABLE 4 Sensitivity and specificity of NSE and SIOOB for diagnosis of stroke

\begin{tabular}{|c|c|c|c|c|}
\hline Study groups & Protein (cut-off) & $\begin{array}{c}\text { Sensitivity \% } \\
(95 \% \mathrm{Cl})\end{array}$ & $\begin{array}{c}\text { Specificity \% } \\
(95 \% \text { CI) }\end{array}$ & $\begin{array}{c}\text { AUC } \\
(95 \% \mathrm{Cl})\end{array}$ \\
\hline \multirow[t]{2}{*}{$\begin{array}{l}\text { Confirmed stroke vs } \\
\text { TIA+mimics }\end{array}$} & $\begin{array}{c}\text { NSE } \\
(14 \mu g / L)\end{array}$ & $\begin{array}{c}53 \% \\
(44-70)\end{array}$ & $\begin{array}{c}64 \% \\
(35-92)\end{array}$ & $\begin{array}{c}0.68 \\
(0.49-0.89)\end{array}$ \\
\hline & $\begin{array}{c}\mathrm{SIOOB} \\
(130 \mathrm{ng} / \mathrm{L})\end{array}$ & $\begin{array}{c}55 \% \\
(43-68)\end{array}$ & $\begin{array}{c}64 \% \\
(25-84)\end{array}$ & $\begin{array}{c}0.60 \\
(0.44-0.76)\end{array}$ \\
\hline \multirow[t]{2}{*}{$\begin{array}{l}\text { Confirmed stroke vs } \\
\text { control }\end{array}$} & $\begin{array}{c}\text { NSE } \\
(14 \mu g / L)\end{array}$ & $\begin{array}{c}53 \% \\
(45-70)\end{array}$ & $\begin{array}{c}79 \% \\
(66-85)\end{array}$ & $\begin{array}{c}0.73^{*} \\
(0.65-0.81)\end{array}$ \\
\hline & $\begin{array}{c}\text { S100B } \\
(130 \mathrm{ng} / \mathrm{L})\end{array}$ & $\begin{array}{c}55 \% \\
(43-68)\end{array}$ & $\begin{array}{c}86 \% \\
(71-89)\end{array}$ & $\begin{array}{c}0.8 \mathrm{I}^{*} \\
(0.74-0.88)\end{array}$ \\
\hline
\end{tabular}

TIA= Transient ischaemic attacks; $\mathbf{A U C}=$ area under the curve; ${ }^{p} \mathrm{p}=0.000 \mathrm{I} ; \mathbf{C l}=$ Confidence interval; $\boldsymbol{\mu g} / \mathbf{L}=$ micrograms per litre; $\mathbf{n g} / \mathbf{L}=$ nanograms per litre 
confirmed stroke were not different when compared to TIA+mimics. This would be expected, due to the increased passage of these proteins into the systemic circulation as a consequence of release and/or secretion subsequent to glial and neuronal damage and the ensuing disruption of the blood-brain barrier. There are several reports indicating that both proteins are markers of glial and neuronal injury in ischaemic stroke and a smaller number of studies demonstrating the role of peripheral markers in haemorrhagic stroke. ${ }^{9-14}$ However these markers are not specific for stroke; raised levels of NSE and SIOOB have also been found in other neurological conditions such as Alzheimer's disease, epilepsy, brain tumours, dementia, schizophrenia and CreutzfeldtJackob disease, among others. ${ }^{15-18}$ The correlation observed between NSE and SIOOB levels in stroke patients supports its association with acute damage of glial and neuronal cells. It was not present in TIA+stroke mimics and control subjects.

Whiteley et al. published a detailed review of the use of blood biomarkers in the diagnosis of ischaemic stroke, where there was great variability in the sensitivity of both NSE and SIOOB (NSE: 55-80; SI00B: 35-60) and specificity of NSE (NSE: $35-100) .{ }^{8}$ Our results are within the range reported in the scientific literature for the sensitivity of NSE and SIOOB, with lower specificity values. The low sensitivity observed is probably related to the inclusion of study subjects who had lacunar strokes, which display values of NSE and SIOOB similar to those of the high-risk control group. The heterogeneity of the types of stroke in most of the studies reported in the review ${ }^{8}$ is probably the underlying cause for the similarity with our results. The timing of blood withdrawal in relation to symptom onset can also introduce variability in the sensitivity reported in different studies. The lower specificity reported is probably due to the fact that it was defined by other authors as a $95 \%$ or $98 \%$ reference interval in subjects without disease, ${ }^{12}$ while our values were calculated on the basis of stroke mimics and for control subjects with a high prevalence of hypertension.

The ROC analysis of serum NSE and SIO0B levels showed optimal values of specificity of $79 \% \quad(95 \%$ confidence interval $[\mathrm{Cl}]: 66-85)$ and $86 \%(95 \% \mathrm{Cl}$ : 7I-89) respectively, when compared with a high-risk control group; the values decreased to $64 \%$ for both proteins when compared with TIA+stroke mimics. The biomarkers were not effective at differentiating acute stroke from other confounding conditions in our study. This is could be due to two main reasons: I) acute stroke patients may not display markedly increased blood markers during the first $\mathbf{2 4}$ hours, especially when stroke severity is not high (as in a lacunar ischaemic stroke), and 2 ) in some neurological conditions which can be mistaken for stroke, brain damage accompanied by an increased release of brain-specific proteins to the circulation can occur by similar mechanisms as in stroke (i.e. neuronal or glial necrosis occurs in patients with brain tumours as well as in patients with ischaemic stroke).

One limitation of this study is the relatively small number of patients who initially presented with suspected stroke but were not ultimately diagnosed with it. It should be taken into account that the low prevalence of mimics could affect the total accuracy and the results cannot be accepted with certainty as representative of unbiased findings. Nevertheless, our results agree with other authors who have stated that elevated levels of NSE and SIOOB in the blood are not specific for stroke, as increases occur in other neurological conditions which are symptomatically similar. ${ }^{12,19}$ As Whiteley stated, the high sensitivities and specificities that have been reported for most blood markers are in part due to the study design which inflates their sensitivity and specificity for a diagnosis of stroke. ${ }^{20}$

To date, no single or panel of blood biomarkers has proven to be of diagnostic relevance for the diagnosis of acute stroke. It was clearly established recently that none of them improved the diagnostic performance of a validated clinical stroke scale. ${ }^{3}$ These blood biomarkers may however prove useful for assessing short and/or long-term prognosis, but this is still controversial and yet to be definitely established. ${ }^{12,21}$ We are now evaluating the association of NSE and SIOOB levels with short-term neurological outcome in this cohort.

Although this study has limitations due to the diagnostic distribution and low internal validity, it has high external validity as the findings concur with those in larger series, thus supporting the evidence indicating that serum levels of NSE and SIOOB do not provide the clinician with appropriate decision-making information for the diagnosis of acute stroke.

\section{Acknowledgements}

This study was funded by the Ministry of Public Health of Cuba. We thank Isabel Fernández and Rosa Guerra (from the Institute of Neurology and Neurosurgery) for technical laboratory assistance. 
S González-García, A González-Quevedo, M Peña-Sánchez, C Menéndez-Saínz, R Fernández-Carriera, M Arteche-Prior, A Pando-Cabrera, O Fernández-Concepción

\section{REFERENCES:}

I Hand PJ, Wardlaw JM, Rowat AM et al. Magnetic resonance brain imaging in patients with acute stroke: feasibility and patient related difficulties. J Neurol Neurosurg Psychiatry 2005; 76:I525-7. http:// dx.doi.org/10.I I36/jnnp.2005.062539

2 Kane I,Whiteley WN, Sandercock PAG et al. Availability of CT and MR for assessing patients with acute stroke. Cerebrovasc Dis 2008; 25:375-7. http://dx.doi.org/I0.1 I59/000I20688

3 Whiteley W. Identifying blood biomarkers to improve the diagnosis of stroke. J $R$ Coll Physicians Edinb 20I I; 4I:I52-4. http://dx.doi. org/I0.4997/JRCPE.20II.207

$4 \mathrm{Kim}$ MH, Kang SY, Kim MC et al. Plasma biomarkers in the diagnosis of acute ischaemic stroke. Ann Clin Lab Sci 2010; 40:336-4I.

5 González-Quevedo A, González García S, Fernández Concepción $\mathrm{O}$ et al. Increased serum S-I00B and neuron specific enolasepotential markers of early nervous system involvement in essential hypertension. Clin Biochem 20I I;44:I54-9. http://dx.doi.org/I0.1016/j. clinbiochem.2010.1 I.006

6 Buergo Zuaznábar MA, Fernández Concepción O. [Clinical guidelines. Cerebrovascular diseases.] Havana, Cuba: Medical Sciences Publisher; 2009. Spanish.

7 jickling GC, Sharp FR. Blood biomarkers of ischaemic stroke Neurotherapeutics 20II; 8:349-60. http://dx.doi.org/I0.1007/ sI33II-0II-0050-4

8 Whiteley W, Tseng MC, Sandercock P. Blood biomarkers in the diagnosis of ischaemic stroke: a systematic review. Stroke 2008; 39:2902-9. http://dx.doi.org/ I0. I I6 I/STROKEAHA. I07.5 I I 26 I

9 Ohira T, Shahar E, Chambless LE et al. Risk factors for ischaemic stroke subtypes. The Atherosclerosis Risk in Communities study. Stroke 2006; 37:2493-8. http://dx.doi.org/I0.I I6I/0I.STR.0000239694.19359.88

10 Marchi N, Rasmussen P, Kapural M et al. Peripheral markers of brain damage and blood-brain barrier dysfunction. Restor Neurol Neuros 2003; 21:109-2I.

I I Selakovic V, Raicevic R, Radenovic L. The increase of neuron-specific enolase in cerebrospinal fluid and plasma as a marker of neuronal damage in patients with acute brain infarction.J Clin Neurosci 2005; 12:542-7. http://dx.doi.org//0.1016/j.jocn.2004.07.019

12 Dassan P, Keir G, Brown MM. Criteria for a clinically informative serum biomarker in acute ischaemic stroke: a review of SI00B. CerebrovascDis 2009;27:295-302.http://dx.doi.org//0.I I59/000I99468
I3 Kim JS, Yoon SS, Kim YH et al. Serial measurement of interleukin-6, transforming growth factor-beta, and S-100 protein in patients with acute stroke. Stroke 1996; 27:1553-7. http://dx.doi. org/I0.II6I/0I.STR.27.9.1553

I4 Brea D, Sobrino T, Blanco $M$ et al. Temporal profile and clinical significance of serum neuron-specific enolase and SI00 in ischaemic and hemorrhagic stroke. Clin Chem Lab Med 2009; 47:1513-8. http://dx.doi.org/10.15I5/CCLM.2009.337

I5 Griffin WS, Yeralan O, Sheng JG et al. Overexpression of the neurotrophic cytokine $\mathrm{SIOO}$ beta in human temporal lobe epilepsy.J Neurochem 1995; 65:228-33. http://dx.doi.org/ 10.1046/ i. I47I-4I59.1995.650I0228.x

16 Lin J, Blake M, Tang $C$ et al. Inhibition of p53 transcriptional activity by the SI00B calcium-binding protein.J Biol Chem 200 I; 276:350374l. http://dx.doi.org// 0.1074/jbc.MI04379200

17 Gottesman RF, Wityk RJ. Brain injury from cardiac bypass procedures. Semin Neurol 2006; 26:432-9. http://dx.doi. org/10.1055/s-2006-948324

I8 Schmitt A, Bertsch T, Henning U et al. Increased serum SI00B in elderly, chronic schizophrenic patients: negative correlation with deficit symptoms. Schizophr Res 2005; 80:305-13. http://dx.doi. org/10.1016/j.schres.2005.04.013

19 Dassan P, Keir G, Brown MM. Criteria for a clinically informative serum biomarker in acute ischaemic stroke: a review of SI00B. CerebrovascDis 2009;27:295-302.http://dx.doi.org/I0.I I59/000I99468

20 Saenger AK, Christenson RH. Stroke biomarkers: progress and challenges for diagnosis, prognosis, differentiation, and treatment. Clin Chem 2010; 56:21-33. http://dx.doi.org/I0.1373/ clinchem.2009.13380I

2I Whiteley W, Wardlaw J, Dennis $M$ et al. Blood biomarkers for the diagnosis of acute cerebrovascular diseases: a prospective cohort study. Cerebrovasc Dis 20II; 32:|4I-7. http://dx.doi. org/10.1159/000328517

22 Whiteley W, Chong WL, Sengupta A et al. Blood markers for the prognosis of ischaemic stroke: a systematic review. Stroke 2009 40:e380-9. http://dx.doi.org/I0.I I6I/STROKEAHA. I08.528752

\section{CONFERENCING AND EVENTS}

The Royal College of Physicians of Edinburgh has a unique blend of rooms providing the perfect location for your conference, meeting or event. The Victorian Great Hall, galleried New Library and the Georgian Cullen Suite are wonderful settings for dinners and receptions. The modern Conference Centre seats up to 300 people in raked seating and is complemented by breakout rooms seating from 10 to 150 people, a keypad voting system and video conferencing. The College provides a stunning setting for weddings and receptions and is licensed for both civil and religious ceremonies. Discounts are available for Fellows and Members, medical conferences and charities.

For more information or for a quotation, please contact the Events Team on +44 (0) I3I 225 7324; email events@rcpe.ac.uk or visit http://www.rcpe-venue.co.uk

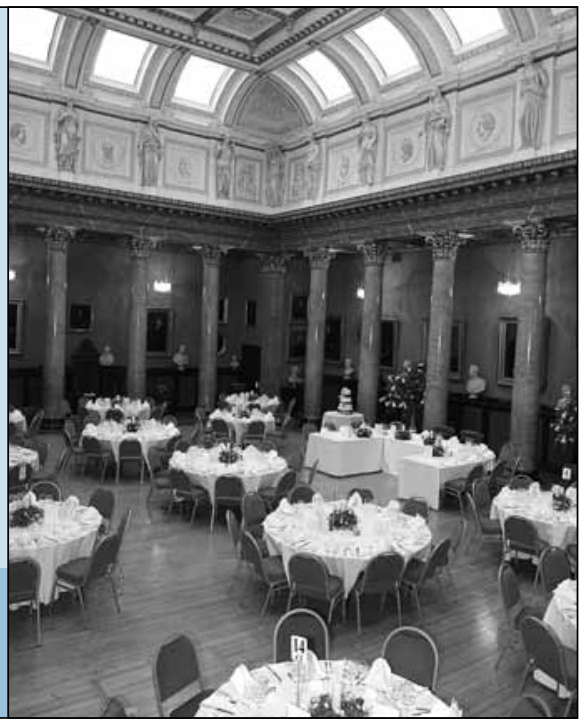

